\title{
INFLUÊNCIA DE ALGUNS PADRÕES DE TELECONEXÃO NA PRECIPITAÇÃO NO NORTE E NORDESTE DO BRASIL
}

\author{
REBOITA, Michelle Simões - reboita@unifei.edu.br \\ Universidade Federal de Itajubá - MG \\ SANTOS, Isimar de Azevedo - isimar@uenf.br \\ Universidade Estadual do Norte Fluminense - RJ
}

\begin{abstract}
RESUMO: Este estudo tem dois objetivos: (1) apresentar uma revisão sobre o que são teleconexões e a influência do fenômeno El Niño-Oscilação Sul (ENOS) e das anomalias de temperatura da superfície do mar (TSM) no oceano Atlântico Tropical no clima da América do Sul bem como (2) avaliar conjuntamente a influência das anomalias de TSM do Pacífico Tropical e do Atlântico Tropical na precipitação das regiões Norte e Nordeste do Brasil, assim como na posição e intensidade da Zona de Convergência Intertropical (ZCIT) no Atlântico. Entre os resultados é mostrado que nem sempre na ocorrência de El Niño há déficit de precipitação nas regiões Norte e Nordeste do Brasil, pois a influência das anomalias de TSM do Atlântico Tropical sul e/ou norte se acopla ao efeito das anomalias de TSM do Pacífico Tropical, alterando ou fortalecendo o sinal das anomalias de precipitação sobre o Brasil tropical.
\end{abstract}

Palavras-chave: teleconexão, precipitação, região Norte e Nordeste do Brasil

TELECONNECTION INFLUENCES IN SOME PRECIPITATION STANDARDS

ABSTRACT: This study has two purposes: (1) to show a review about teleconnections and the influence of El Niño-Southern Oscillation (ENSO) and of the anomalies of sea surface temperature (SST) in the tropical Atlantic Ocean in South America climate and (2) to assess the influence of SST anomalies in the tropical Pacific and tropical Atlantic in the precipitation over Northern and Northeastern Brazil as well as the position and intensity of the Intertropical Convergence Zone (ITCZ) over the Atlantic Ocean. Among the results it is shown that in El Niño events not always there is a precipitation deficit over Northern and Northeastern Brazil because the influence of SST anomalies in the north and-or south tropical Atlantic couples to the effect of SST anomalies in the tropical Pacific changing or strengthening the signal of precipitation anomalies over tropical Brazil.

Keywords: teleconnection, precipitation, Northern and Notheastern Brazil

\section{O Papel das Teleconexões no Clima}

O termo teleconexão se refere à ligação entre anomalias climáticas locais e forçantes localizadas geralmente a grandes distâncias. De acordo com Liu e Alexander (2007), as teleconexões são causadas pela propagação de ondas e transporte de energia na atmosfera e nos oceanos. Segundo estes autores, as teleconexões permitem à atmosfera atuar como uma ponte entre as diferentes partes do oceano, enquanto o oceano atuaria como um túnel ligando as diferentes regiões atmosféricas. O primeiro uso reconhecido do termo teleconexão foi por Ångström (1935) em referência ao dipolo de pressão atmosférica entre a Islândia e os Açores, que é conhecido atualmente por 
Oscilação do Atlântico Norte (em inglês, North Atlantic Oscillation - NAO). Entretanto, o uso do termo teleconexão só começou a se disseminar com o trabalho de Bjerknes, no final dos anos de 1960, sobre os impactos de grande escala do fenômeno El NiñoOscilação Sul (ENOS; BJERKNES, 1969). No início dos anos de 1980 foram publicados vários estudos sobre a associação dos padrões de teleconexão com a variabilidade da temperatura da superfície nos oceanos tropicais (exemplo, HOREL E WALLACE, 1981). Além disso, essa associação foi relacionada com a teoria da dispersão de ondas de Rossby (exemplo, HOSKINS E KAROLY, 1981). Nas décadas de 1980 e 1990, estudos indicaram que a convecção tropical no oceano Pacífico dispara um trem de ondas deste setor em direção a América do Sul e o chamaram de modo do Pacífico - América do Sul (Pacific-South American Mode, PSA). De acordo com Mo e Higgins (1998), o modo PSA apresenta dois padrões: PSA1 e PSA2. O PSA1 está associado com a intensificação da convecção no Pacífico Central entre $140^{\circ} \mathrm{E}$ e $170^{\circ} \mathrm{W}$ e a supressão de convecção sobre o oceano Índico, padrão que se assemelha com o do fenômeno ENOS. Já o PSA2 está associado com a intensificação da convecção no Pacífico Central estendendo-se de $160^{\circ} \mathrm{E}$ a $150^{\circ} \mathrm{W}$, ligeiramente ao sul do equador, e com a supressão no Pacífico Oeste.

Existem vários outros padrões de teleconexão, além do ENOS e dos padrões PSA, e entre eles se encontram o Modo Anular Sul (MAS; THOMPSON E WALLACE, 2000; REBOITA ET AL., 2009), a Oscilação Decadal do Pacífico (ODP; MANTUA ET AL., 1997), 0 dipolo de temperatura da superfície do mar no oceano Índico (SAJI ET AL., 1999) e o dipolo de temperatura da superfície do mar no oceano Atlântico Tropical (MOURA E SHUKLA, 1981).

No contexto das teleconexões, o presente estudo tem como objetivo diagnosticar a influência conjunta do ENOS e das anomalias da temperatura da superfície do mar (TSM) no Atlântico Tropical Norte e Sul no regime sazonal de precipitação das regiões Norte e Nordeste do Brasil bem como na Zona de Convergência Intertropical, no período de 1979 a 2011. Entretanto, antes é apresentada uma revisão da literatura sobre o ENSO e as anomalias de TSM no Atlântico Tropical.

\section{O Fenômeno El Niño-Oscilação Sul}

O fenômeno El Niño-Oscilação Sul (ENOS; PHILANDER, 1985) é o principal modo de variabilidade oceano-atmosfera em escala global (TRENBERTH E CARON, 2000; GRIMM E AMBRIZZI, 2009). O ENOS é um processo de acoplamento entre o oceano e a atmosfera causado pela redistribuição de calor e momento no Pacífico equatorial (MCPHADEN, 2002). O ENOS perturba a circulação zonal de Walker e com isso afeta a convecção tropical, o que causa distúrbios na circulação atmosférica global e, consequentemente, no clima (PHILANDER, 1990; TRENBERTH, 1997; MCPHADEN, 2002 ). A componente atmosférica do ENOS é chamada de Oscilação Sul e a oceânica de El Niño (PHILANDER, 1985). Um evento El Niño (EN) é caracterizado pelo aumento da TSM no setor centro-leste do Pacífico Tropical. Esse aquecimento favorece o decréscimo da pressão atmosférica no Pacífico Tropical Leste em relação ao Pacífico Tropical Oeste; 
nesse caso tem-se a fase negativa da Oscilação Sul e a fase positiva do ENOS. A La Niña (LN) é caracterizada pelo resfriamento da TSM no setor centro-leste do Pacífico Tropical, onde também haverá aumento na pressão atmosférica; nessa situação tem-se a fase positiva da Oscilação Sul e negativa do ENOS. Na fase positiva do ENOS (EN) é esperado enfraquecimento dos ventos alísios, enquanto que na fase negativa (LN), um fortalecimento, quando comparado ao padrão climatológico.

Em anos sem a ocorrência de ENOS (denominados de anos normais ou neutros), o padrão climatológico da célula de circulação zonal de Walker (que na verdade é constituída por seis células no globo, Figura 1a) é caracterizado por movimentos

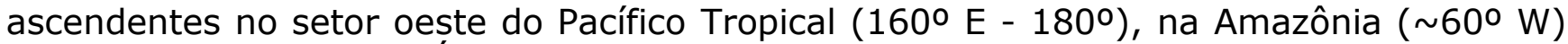
e próximo ao oeste da África. Já os movimentos subsidentes ocorrem próximo à costa oeste da América do Sul $\left(\sim 90^{\circ} \mathrm{W}\right)$, no oceano Atlântico a cerca de $0^{\circ}$ e próximo ao setor leste da África. A Figura 1 mostra como os eventos EN modificam a circulação zonal de Walker. Durante os episódios de EN, a convecção tropical é deslocada do setor oeste do Pacífico para o setor central-leste (Fig. 1b). Com isso, movimentos subsidentes podem ocorrer sobre o norte da América do Sul e oceano Atlântico (GRIMM E AMBRIZZI, 2009; pg. 164). No caso da Amazônia, eles se contrapõem aos movimentos ascendentes climatológicos da célula de Walker (Fig. 1a). Já no nordeste do Brasil e Atlântico Tropical, eles intensificam a subsidência. Portanto, em anos de EN pode ocorrer redução da atividade convectiva e da precipitação nas regiões citadas. Em episódios de LN a convecção tropical no Pacífico Oeste é intensificada em relação aos anos normais (figura não mostrada). Esse padrão fortalece a célula de Walker do Pacífico. Portanto, a atividade convectiva na Amazônia é intensificada, o que pode favorecer a ocorrência de precipitação acima da climatologia em anos de LN. As representações esquemáticas da Figura 1 são suportadas por estudos como os de Rao e Hada (1990), Souza e Ambrizzi (2002), Foley et al. (2002) e Grimm e Tedeschi (2009) que indicam que na ocorrência de eventos EN (LN) há deficiência (abundância) de precipitação na estação chuvosa das regiões Norte e Nordeste do Brasil.

a) Circulação de Walker (DJF): Anos Neutros

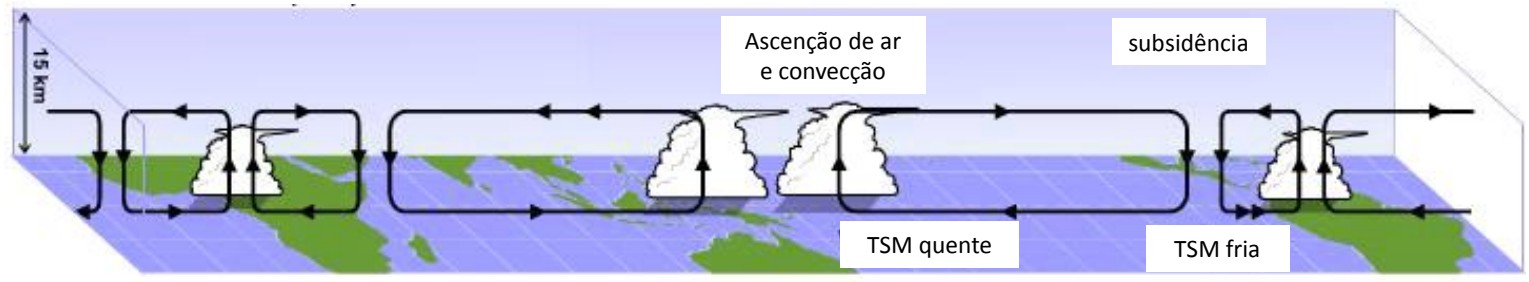

b) Circulação de Walker (DJF): Anos de El Niño

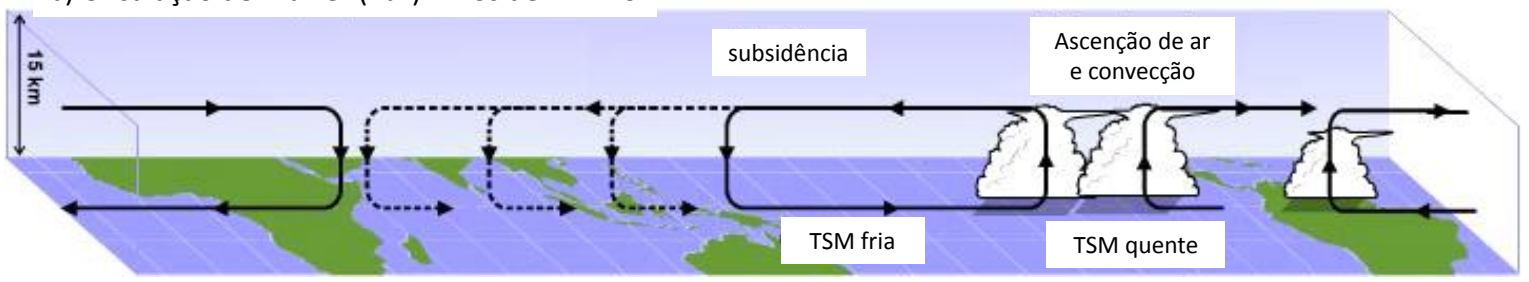

Figura 1 Diagrama esquemático da célula de circulação zonal de Walker em DJF considerando (a) anos neutros e (b) anos com ocorrência de eventos El Niño. Adaptado de http://www.personal.psu.edu/czn115/blogs/meteo241/2\%20Walker\%20Citculation\%20and\%20El\%20Nino.j peg 


\section{Anomalias de tSM no AtLÂntico Tropical}

Embora os efeitos do ENOS sejam observacionalmente evidentes na América do Sul, não se deve avaliar a precipitação nesta região sem levar em consideração o padrão das anomalias de TSM no Atlântico Tropical. Como será mostrado, o padrão das anomalias de precipitação sobre o continente pode diferir nos casos de EN e de LN em que ocorram concomitantemente anomalias positivas ou negativas de TSM no Atlântico Tropical Sul (Tropical Southern Atlantic - TSA) ou no Atlântico Tropical Norte (Tropical Northern Atlantic - TNA).

Moura e Shukla (1981) foram provavelmente os primeiros autores a mostrarem a existência de um dipolo meridional de TSM no Atântico Tropical (Fig. 2a), isto é, ocorrência de anomalias positivas (negativas) de TSM no TSA e negativas (positivas) no TNA. Estudos posteriores como o de Enfield et al. (1999) ressaltaram que o padrão de dipolo de TSM do Atlântico Tropical não é muito frequente, ocorrendo apenas em 12 a $15 \%$ do tempo. Porém, as situações de não-dipolo, que também implicam num gradiente meridional de TSM no Atlântico Tropical, são mais frequentes (um exemplo é dado na Fig. 2b). Nesse contexto, Kane (1992) apresentou evidências de que a variabilidade da precipitação em Fortaleza está melhor associda com as anomalias de TSM no TSA do que no TNA. Marengo et al. (2008) também mostraram que a seca ocorrida no sudoeste da Amazônia em 2005, ano considerado neutro, foi decorrente de uma anomalia positiva de TSM no TNA. As anomalias positivas de TSM enfraqueceram os alísios de nordeste reduzindo o transporte de umidade do Atlântico Tropical para o continente. Já, Cavalcanti (2012) mostrou que as anomalias positivas de precipitação sobre o nordeste do Brasil em abril de 2009 estavam associadas a um dipolo de TSM com anomalias positivas (negativas) dessa variável no TSA (TNA).

a)

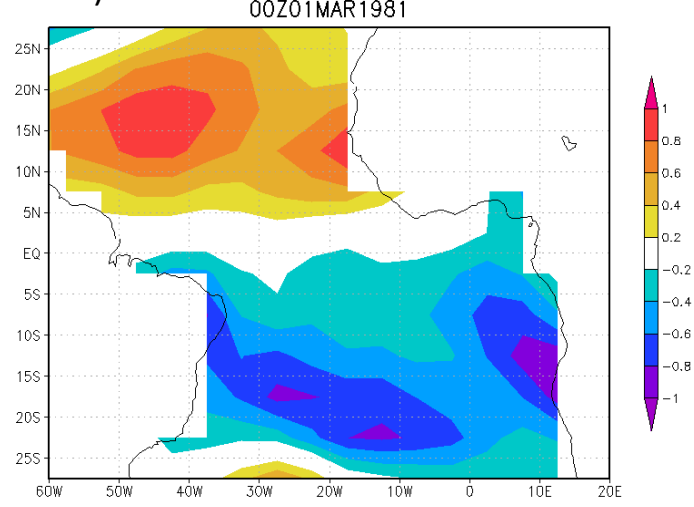

b)

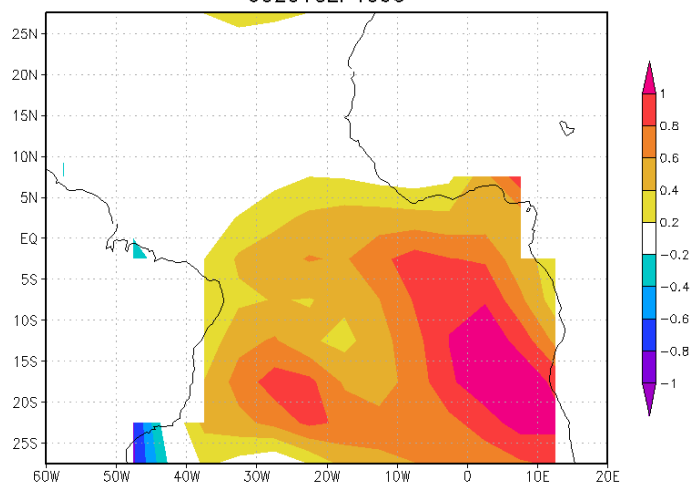

Figura 2 a) Exemplo de dipolo de TSM $\left({ }^{\circ} \mathrm{C}\right)$ no Atlântico Tropical, mostrando anomalias negativas de TSM no setor sul e positivas no setor norte desse oceano, e b) Exemplo de ocorrência de anomalias de TSM somente no setor sul do Atlântico Tropical. Dados obtidos de Kaplan Extended SST V2 (http://www.esrl.noaa.gov/psd/data/gridded/data.kaplan_sst.html). 
De acordo com Yoon e Zeng (2010) somente uma fração da variabilidade da precipitação na bacia Amazônica é explicada pelo ENOS, sendo importante a avaliação conjunta da influência da TSM do Atântico Tropical nessa região. Isso corrobora com o estudo de Uvo et al. (2000) que verificaram que a previsão de precipitação na bacia Amazônica através de redes neurais melhora quando as TSMs do Atlântico Tropical também são utilizadas. Yoon e Zeng (2010), para avaliarem a influência das anomalias de TSM do Atlântico Tropical na precipitação na bacia Amazônica, primeiramente removeram a média climatológica dos dados de precipitação após os filtraram com um filtro passa-baixa de 18 meses. Ao computarem a correlação dessa nova série de precipitação com as anomalias positivas de TSM no TNA obtiveram redução da precipitação na bacia Amazônica e nordeste do Brasil. Por outro lado, quando computaram a correlação com as anomalias positivas de TSM no TSA, notaram anomalias positivas de precipitação que se restringiram ao litoral do nordeste do Brasil e oeste da Amazônia.

Os estudos de Uvo et al. (1998), Pezzi e Cavalcanti (2001) e Andreoli e Kayano (2007) são outros exemplos de trabalhos que analisam o efeito conjunto das anomalias de TSM ocorridas nos oceanos Pacífico Tropical e Atlântico Tropical no clima da América do Sul. Pezzi e Cavalcanti (2001) realizaram quatro grupos de simulações numéricas com o modelo de circulação geral da atmosfera CPTEC-COLA usando como condições de fronteira: (a) anomalias de TSM no Pacífico Tropical representando condições de EN e no Atlântico Tropical com dipolo de TSM sendo ora com anomalias positivas no TSA e ora negativas e b) anomalias de TSM no Pacífico Tropical representando condições de LN e no Atlântico Tropical com dipolo de TSM sendo ora com anomalias positivas no TSA e ora negativas. O período de estudo compreendeu a estaçao chuvosa do Nordeste do Brasil (março-abril-maio). O EN e o dipolo de TSM no Atlântico Tropical com anomalias positivas no TNA resultam em condições secas sobre o norte da América do Sul, o que inclui o Nordeste do Brasil e a Amazônia. Já quando as anomalias de TSM são positivas no TSA, há precipitação acima da normal apenas no norte da região Nordeste enquanto os demais setores tropicais do continente apresentam chuva abaixo da média. No caso de LN e anomalias positivas de TSM no TNA ocorre precipitação abaixo da média no nordeste do Brasil e no leste da Amazônia. Utilizando anomalias positivas de TSM no TSA, eles encontraram anomalias positivas de precipitação no Nordeste do Brasil e anomalias negativas no oeste da Amazônia.

Kayano e Andreoli (2007) encontraram evidências de que, sob condições de EN, chuvas acima do normal podem ocorrer na região Nordeste do Brasil, em especial na Bahia, se as águas superficiais do setor equatorial-tropical do oceano Atlântico Sul estiverem anomalamente aquecidas, o que no presente estudo é indicado por TSA positiva. Segundo elas, as águas superficiais mais quentes do que o normal no Atlântico Sul equatorial-tropical podem reforçar as ações de fenômenos sinóticos tais como frentes frias em lenta movimentação e vórtices ciclônicos subtropicais dos altos níveis. Por outro lado, sob condições de LN, Kayano e Andreoli (2007) sugerem que inesperadas anomalias negativas da chuva no norte e nordeste da América do Sul nos meses de março e abril podem ser devidas à variabilidade da TSM do Atlântico Tropical, que desempenha papel mais importante do que a variabilidade da TSM do Pacífico Tropical no controle climático de tal região. Em síntese, os vários trabalhos mencionados apontam para uma variabilidade da precipitação no Norte e Nordeste do Brasil quando as 
diferentes fases do ENOS ocorrem concomintantemente com diferentes padrões de TSM no Atlântico Tropical. Com base nisso, o presente estudo mostrará uma análise conjunta do ENOS com as anamalias de TSMs do TSA e TNA.

\section{CONTROLE do ENOS E dA TSM dO ATLÂNTICO TROPICAL}

Para as análises que serão apresentadas a seguir, foram utilizados dados de precipitação mensal, no período de 1979 a 2011, da reanálise do NCEP/CFSR (http://cfs.ncep.noaa.gov/cfsr/), com resolução horizontal de 0,50 de latitude e longitude. Conforme Silva et al. (2011), essa reanálise representa melhor a chuva na América do Sul do que as reanálises "1" e " 2 " do National Centers for Environmental Prediction (NCEP) e, dentre as melhorias, tem-se a não superestimação da precipitação no Nordeste do Brasil no verão.

As anomalias de TSM nos oceanos Pacífico Tropical e Atlântico Tropical foram identificadas através da utilização dos índices Oceanic Niño Index (ONI) que computa as anomalias de TSM na região de Niño 3.4, Tropical Northern Atlantic Index (TNA) e Tropical Southern Atlantic Index (TSA). O TNA e TSA são descritos em Enfieldet al. (1999). Os três índices são disponibilizados pelo Climate Prediction Center (CPC) do NCEP (http://www.esrl.noaa.gov/psd/data/climateindices/list/).

No presente estudo foi avaliada conjuntamente a influência das anomalias de TSM do Pacífico Tropical e do Atlântico Tropical na precipitação das regiões Norte e Nordeste do Brasil, assim como na posição e intensidade da Zona de Convergência Intertropical (ZCIT) do Atlântico. Para tanto, foi identificada a ocorrência de anomalias positivas (consideradas aqui como eventos de EN) ou negativas (consideradas aqui como eventos de LN) da TSM no Pacífico Tropical juntamente com: (a) anomalias positivas do TSA, (b) anomalias negativas do TSA, (c) anomalias positivas do TNA, (d) anomalias negativas do TNA, (e) anomalias de TSM mais quentes no TSA do que no TNA e ( $f$ ) anomalias de TSM mais frias no TSA do que no TNA. Para estas análises utilizaram-se índices combinados, obtidos de três maneiras: (a) um índice obtido pelo produto do índice ONI (representativo do fenômeno ENOS) pelo índice TSA a cada mês, (b) um índice obtido pelo produto do ONI pelo índice TNA a cada mês, e (c) um índice dado pelo produto do ONI pela diferença TSA menos TNA a cada mês. Neste último caso, a diferença entre TSA e TNA é um indicativo do gradiente meridional de temperatura do Atlântico Tropical. Em seguida, para cada trimestre representativo das estações do ano, foram calculadas as médias ponderadas da precipitação na área de interesse, sendo o fator de ponderação o índice produto ONI vezes TSA ou ONI vezes TNA ou ainda ONI vezes a diferença TSATNA. Com esta técnica de médias ponderadas, usando como fator de ponderação um índice produto indicativo das intensidades do ENOS e das anomalias de TSA, de TNA ou da sua diferença, obtém-se uma climatologia regionalizada da precipitação, tendo em conta a intensidade dos controles físicos exercidos pelas conexões tropicais tanto do Pacífico quanto do Atlântico. Finalmente, são determinadas as diferenças gráficas entre as médias ponderadas trimestrais da precipitação e a média climatológica da precipitação 
no mesmo trimestre. Assim sendo, pode-se dizer que as anomalias apresentadas a seguir são indicativas da resposta física da chuva nas regiões Norte e Nordeste do Brasil tanto ao ENOS quanto à TSA ou à TNA, porque a média que permitiu o cálculo das anomalias foi uma média ponderada pelo índice ONI, mais ou menos intenso, multiplicado pelo índice TSA ou TNA mais ou menos intenso, ou ainda por sua diferença mais ou menos intensa. No caso do índice baseado na diferença entre as anomalias do TSA e do TNA (TSA - TNA), os valores positivos (negativos) indicam que o TSA está mais quente (frio) do que o TNA.

As estações do ano no Hemisfério Sul são aqui representadas pelos trimestres setembro-outubro-novembro (SON) para a primavera, dezembro-janeiro-fevereiro (DJF) para o verão e março-abril-maio (MAM) para o outono. O inverno não é analisado por ser a época de estiagem tanto na Amazônia quanto na Região Nordeste do Brasil.

\section{Controle das Teleconexões na Primavera}

O trimestre SON, aqui indicativo da primavera tropical, embora represente mais adequadamente a primavera do Hemisfério Sul fora dos trópicos, é a época em que se inicia a estação chuvosa na Amazônia, começando a partir do setor noroeste dessa região (VERA ET AL., 2006; REBOITA ET AL., 2010).

A Figura 3 apresenta as anomalias da precipitação na faixa tropical sobre a América do Sul e oceano Atlântico quando as anomalias positivas de TSM no Pacífico Tropical (aqui consideradas como EN) coincidem com a (a) TSA $>0$, (b) TSA $<0$, (c) TNA $>0$, (d) TNA<0, (e) TSA $>$ TNA e (f) TSA<TNA. De forma geral, a Figura 3 mostra déficit de precipitação no setor tropical do continente e na ZCIT, o que era esperado já que em períodos de EN tende a ocorrer inibição da convecção tanto na Amazônia quanto na região Nordeste do Brasil. Numa análise mais detalhada, contudo, nota-se que a região Norte do Brasil é a mais afetada por condições secas na combinação EN e TSA $<0$ (Fig. 3b), resultado que concorda com Pezzi e Cavalcanti (2001). Porém, tais condições secas enfraquecem quando da ocorrência de TSA>0 (Fig. 3a) e chega a ocorrer excesso de precipitação no oeste da Amazônia quando TNA>0 (Fig. 3c). Com relação à região Nordeste do Brasil, em geral, predominam anomalias negativas de precipitação no Maranhão, Piauí e litoral leste nas situações de TSA $>0$ (Fig. 3a), TSA $<0$ (Fig. 3b) e TNA $>0$ (Fig. 3c). Nessas situações a ZCIT também aparece enfraquecida ou deslocada para norte. É interessante destacar que a ocorrência de TSMs mais elevadas no TSA do que no TNA não favorece a chuva no oeste da América do Sul (Fig. 3e), o que ocorre quando as anomalias de TSM no TSA são menores do que no TNA (Fig. 3f). Nessa última situação, também há déficit de chuva entre o leste da Amazônia e o nordeste do Brasil.

A Figura 4 é similar a Figura 3, mas para os casos de anomalias negativas de TSM no Pacífico Tropical, aqui referidos como LN. Conforme mencionado anteriormente, LN influencia positivamente a precipitação no setor tropical da América do Sul e isso pode ser observado na Figura 4. Anomalias positivas de precipitação não ocorrem quando se tem a combinação LN e TSA<0 (Fig. 4b), embora nessa situação sejam registradas as maiores anomalias positivas em direção aos subtrópicos (nos estados de 
Goiás e Minas Gerais). Destaca-se que no Ceará e nos estados do leste da região Nordeste a precipitação não é afetada pela combinação da LN com a TSM do Atlântico Topical sul ou norte (Fig. 4a-f). Com relação à ZCIT, esta aparece enfraquecida na situação LN e TSA<0 (Fig. 4b) e mais intensa no centro-oeste do Atlântico Tropical nas situações LN e TNA<0 (Fig. 4d) e LN e TSA>TNA (Fig. 4e). Quando os dois setores do Atlântico Tropical são analisados conjuntamente, nota-se que as anomalias positivas de precipitação sobre o continente são mais intensas na situação TSA<TNA (Fig. 4f).

(a)

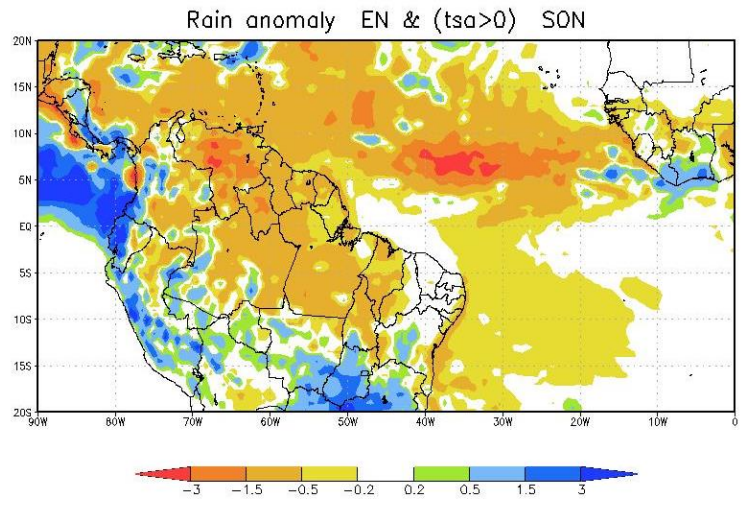

(c)

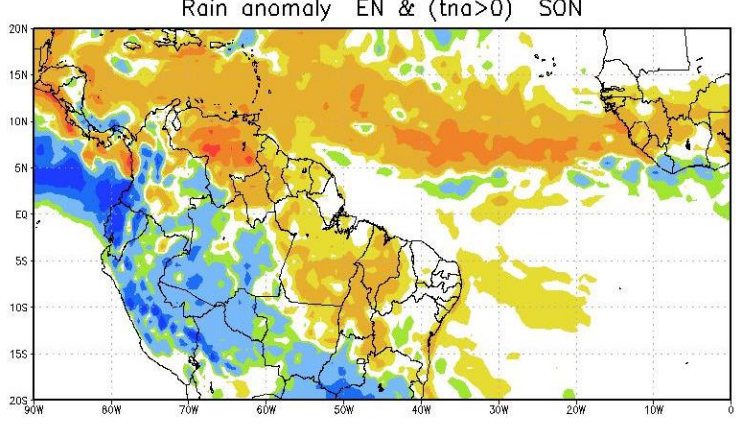

(e)

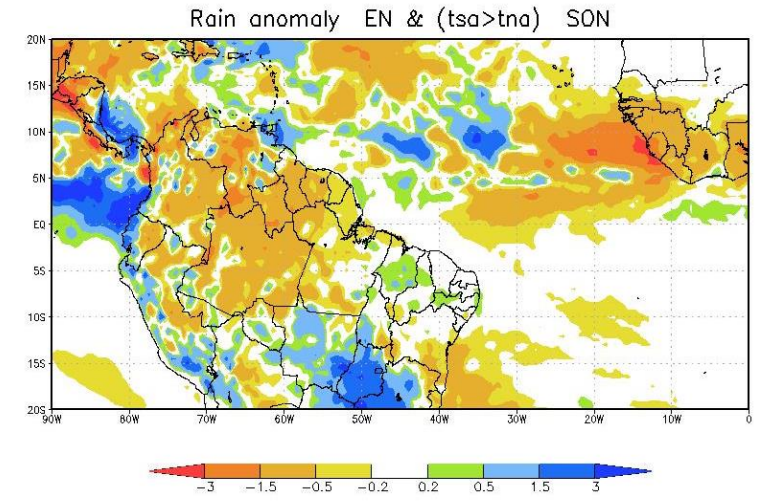

(b)

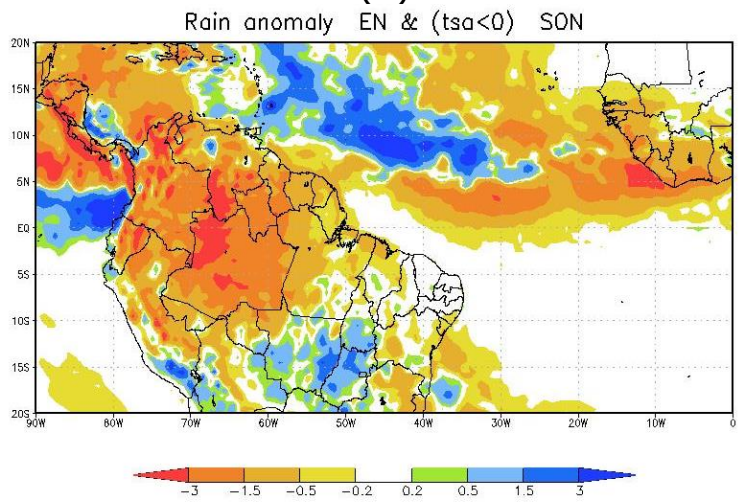

(d)

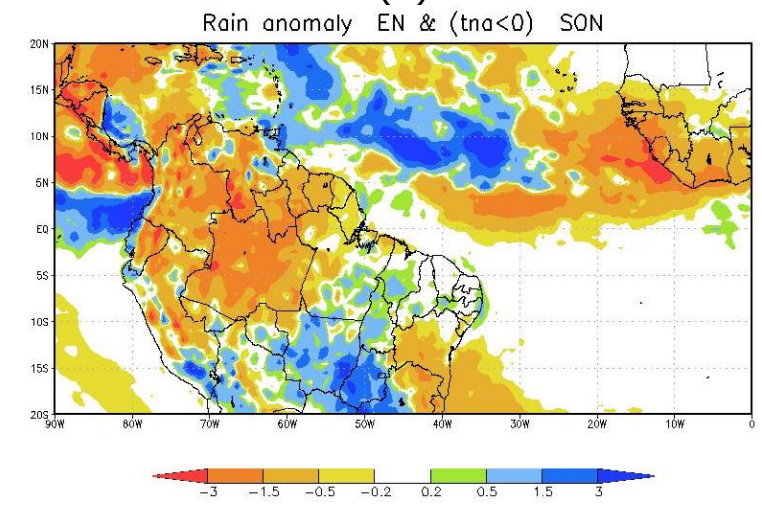

(f)

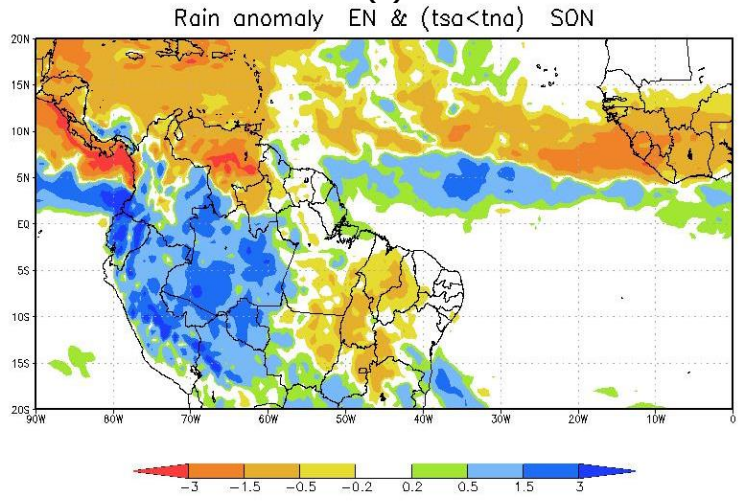

Figura 3 Anomalias da precipitação tropical ( $\mathrm{mm} \mathrm{dia}^{-1}$ ) em setembro-outubro-novembro de 1979 a 2011, com o El Niño coincidindo com: (a) TSA positiva, (b) TSA negativa, (c) TNA positiva e (d) TNA negativa, (e) diferença TSA-TNA positiva, e (f) diferença TSA-TNA negativa. 
(a)

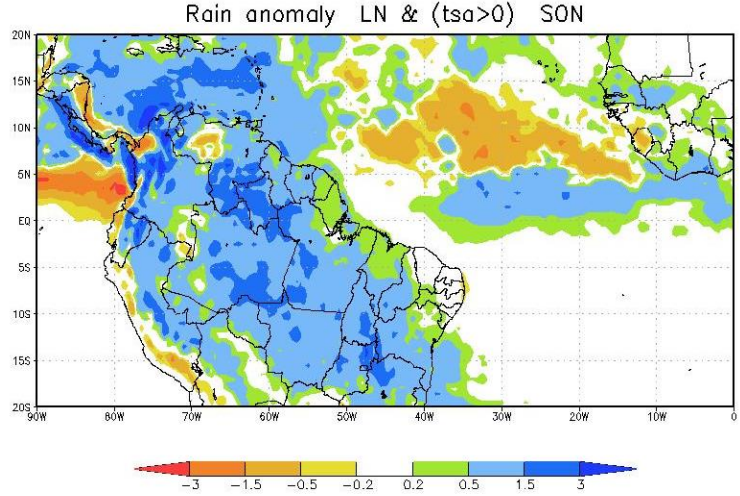

(c)

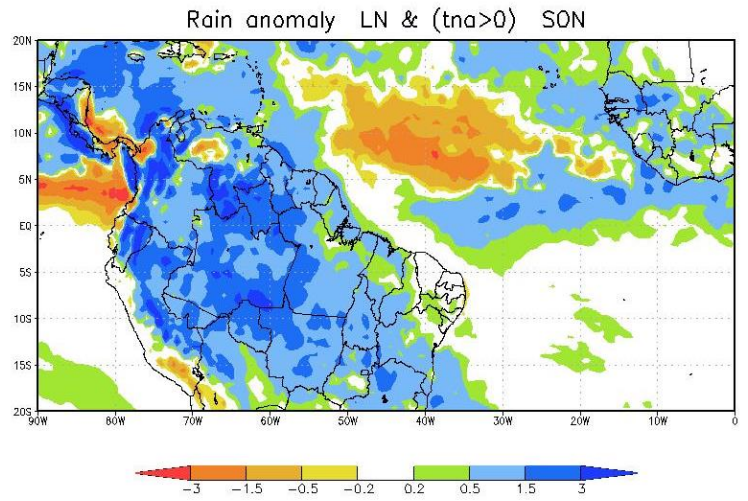

(e)

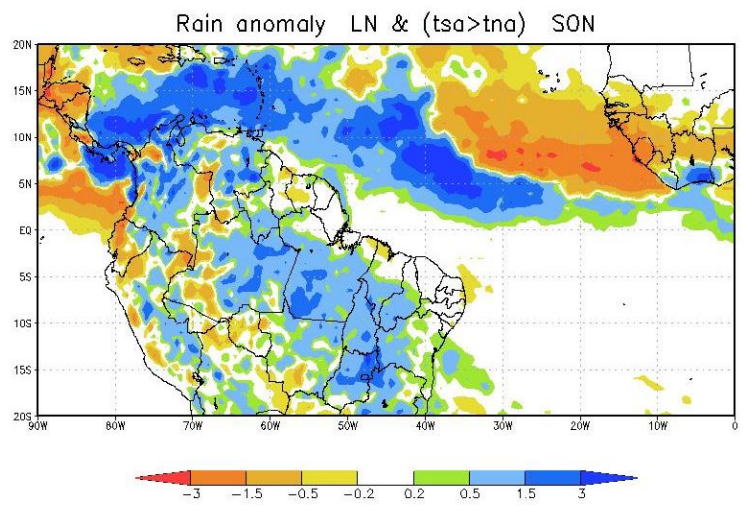

(b)

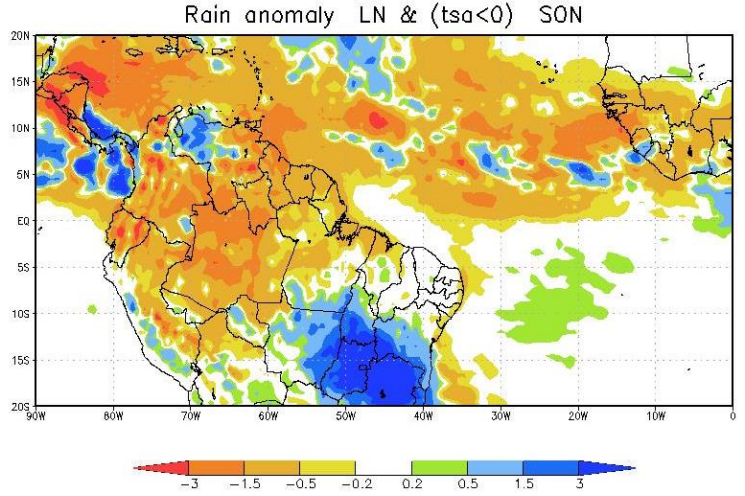

(d)

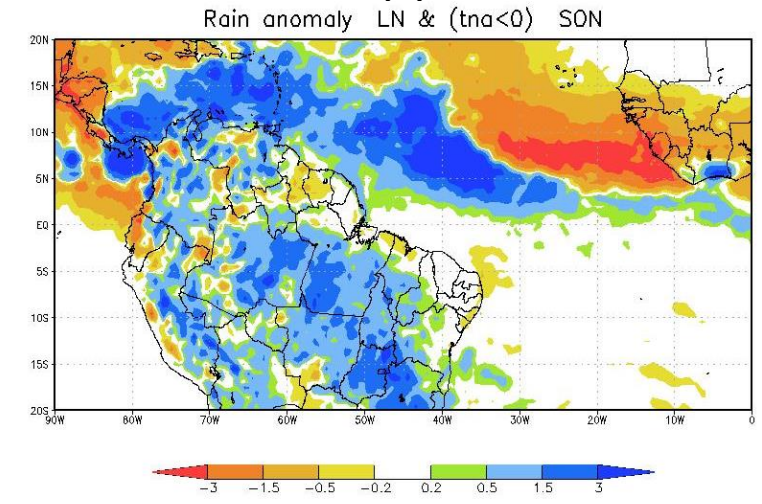

(f)

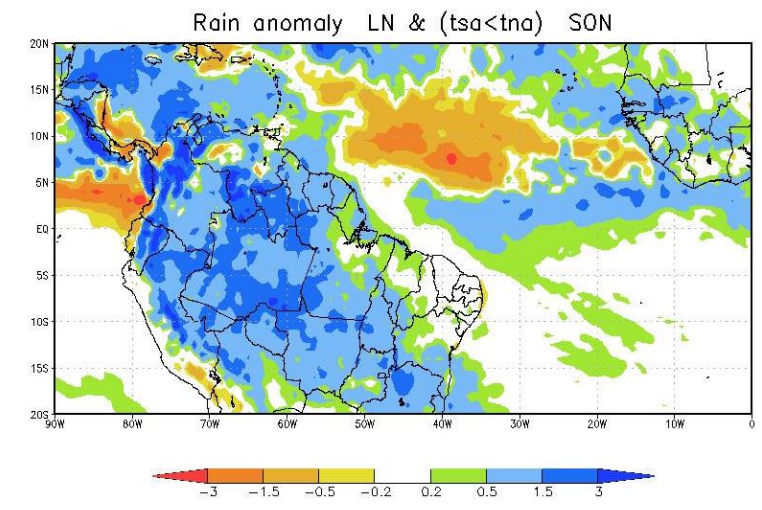

Figura 4 Anomalias da precipitação tropical $\left(\mathrm{mm} \mathrm{dia}^{-1}\right)$ em setembro-outubro-novembro de 1979 a 2011 , com a La Niña coincidindo com: (a) TSA positiva, (b) TSA negativa, (c) TNA positiva e (d) TNA negativa, (e) diferença TSA-TNA positiva, e (f) diferença TSA-TNA negativa. 


\section{Controle das Teleconexões no Verão}

No trimestre DJF a atividade convectiva aumenta na Amazônia e se estende em direção aos subtrópicos, caracterizando a fase madura da Monção Sul-Americana (VERA ET AL., 2006). Esta estação chuvosa também pode ser influenciada pelas TSMs dos oceanos tropicais. A Figura 5 mostra que, mesmo em condições de EN, se o TSA está anomalamente frio, isto é, as anomalias no TSA são negativas, podem ocorrer chuvas em toda a região Nordeste nesta época do ano, e a ZCIT aparece ligeiramente deslocada para norte (Fig. 5b). Nota-se também que, se as TSMs no TSA ou no TNA forem quentes (Figs. 5a, 5c), a ZCIT é enfraquecida, mas se as TSMs do Atlântico Tropical forem frias, a ZCIT desloca-se para norte de sua posição normal (Figs. 5b, 5d). Ressalta-se que as regiões Norte e Nordeste do Brasil são mais afetadas por condições secas na combinação EN e TNA<0 (Fig. 5d) e um padrão das anomalias de precipitação similar ao dessa configuração ocorre com EN e TSA>TNA (Fig. 5e). Na configuração EN e TSA<TNA (Fig. 5f) as anomalias positivas de precipitação passam a cobrir todo o Nordeste do Brasil.

Considerando as condições do Pacífico Tropical com anomalias frias (LN), que são favoráveis à chuva na América do Sul tropical, vê-se na Figura 6 que, dependendo das condições do Atlântico Tropical, pode ocorrer redução da precipitação em alguns setores do continente. Por exemplo, a região Nordeste do Brasil e os estados do Pará, Amapá e Tocantins têm os maiores déficits de precipitação quando as TSMs do TSA são anomalamente frias (Fig. 6b). Já o setor oeste da América do Sul é dominado por anomalias positivas de precipitação. A situação de TSA $<0$ também é a que mais impacta a ZCIT com anomalias negativas (Fig. 6b). Com TSA $>0$, todo setor tropical da América do Sul é dominado por anomalias positivas de precipitação (exceto Minas Gerais, Fig. 6a). Com relação ao TNA, águas quentes nesse oceano implicam em déficit de precipitação entre o oeste do Pará e Piauí (Fig. 6c) enquanto que as águas frias levam a déficit de precipitação entre o Centro-Oeste do Brasil e a Bahia (Fig. 6d). Quando os dois setores do Atlântico Tropical são analisados concomitantemente, TSA>TNA é importante para o aumento da chuva no Norte do Nordeste do Brasil e para a ZCIT (Fig. 6e), ao passo que TSA<TNA produz condições opostas (Fig. 6f). Essa última configuração também está associada com mais chuva na Amazônia se comparada com a condição TSA>TNA. 
ISSN: 1980-055x (Impressa) 2237-8642 (Eletrônica)

(a)

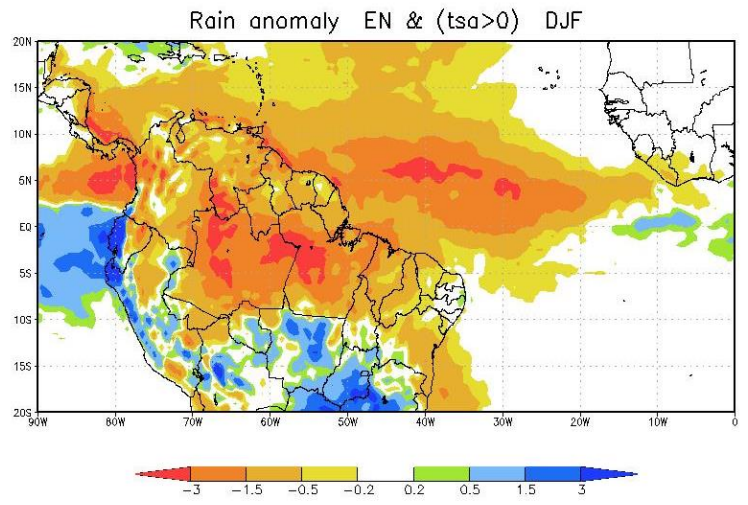

(c)

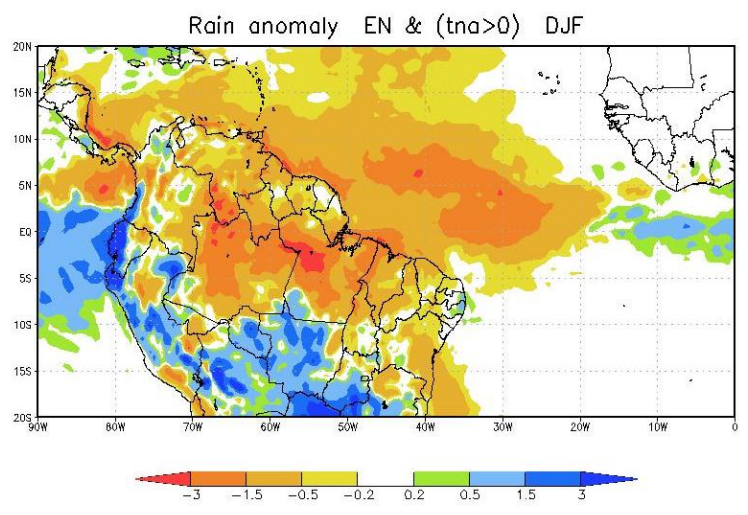

(e)

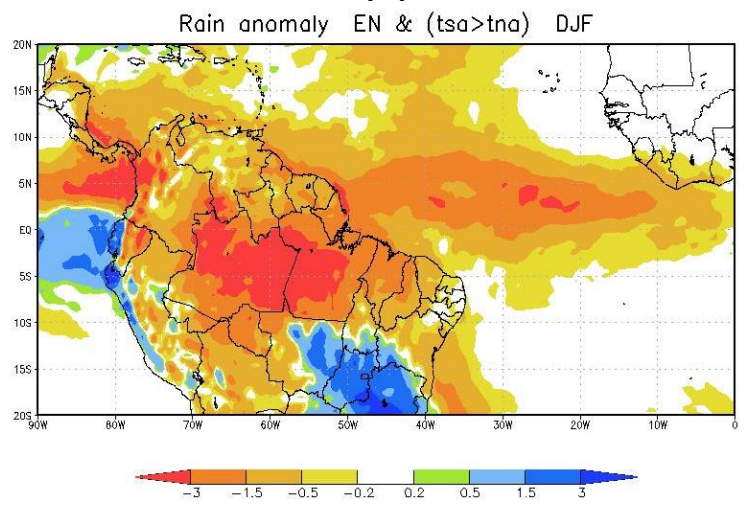

(b)

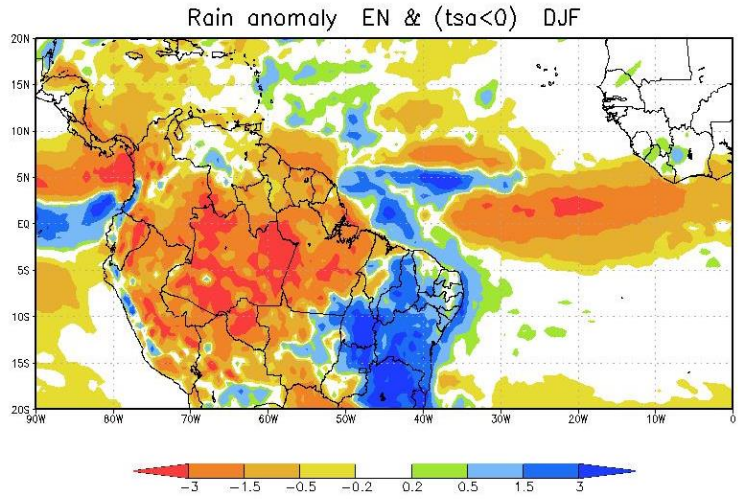

(d)

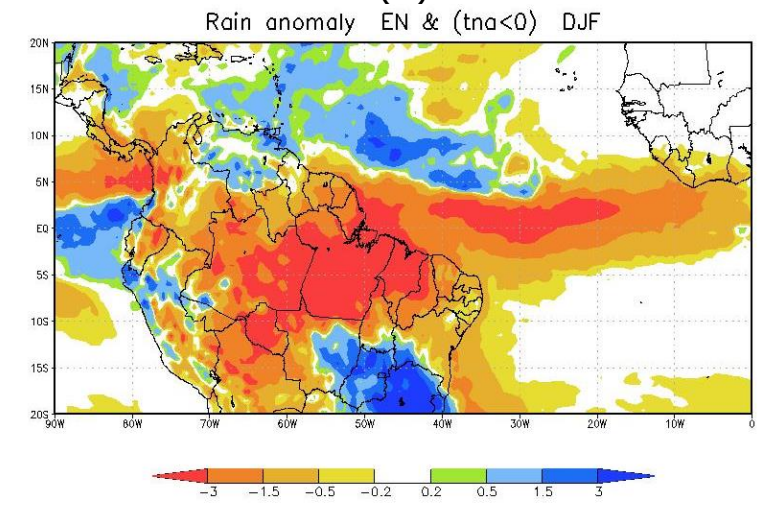

(f)

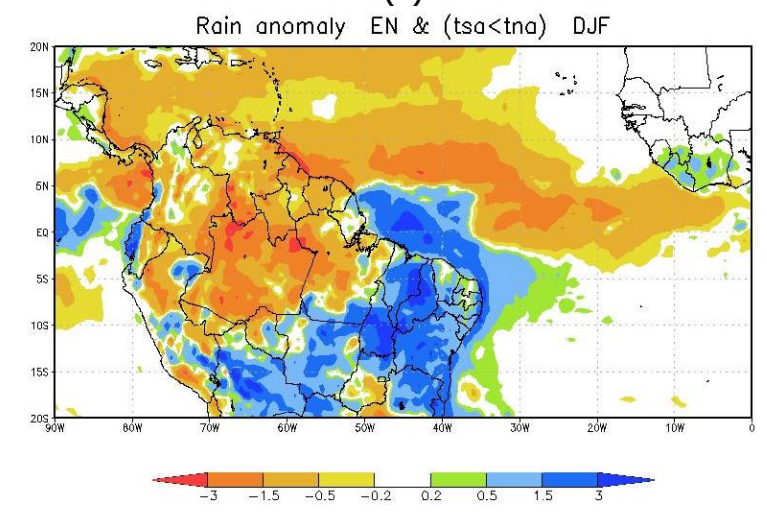

Figura 5 Anomalias da precipitação tropical $\left(\mathrm{mm} \mathrm{dia}^{-1}\right)$ em dezembro-janeiro-fevereiro de 1979 a 2011, com o El Niño coincidindo com: (a) TSA positiva, (b) TSA negativa, (c) TNA positiva e (d) TNA negativa, (e) diferença TSA-TNA positiva, e (f) diferença TSA-TNA negativa. 
(a)

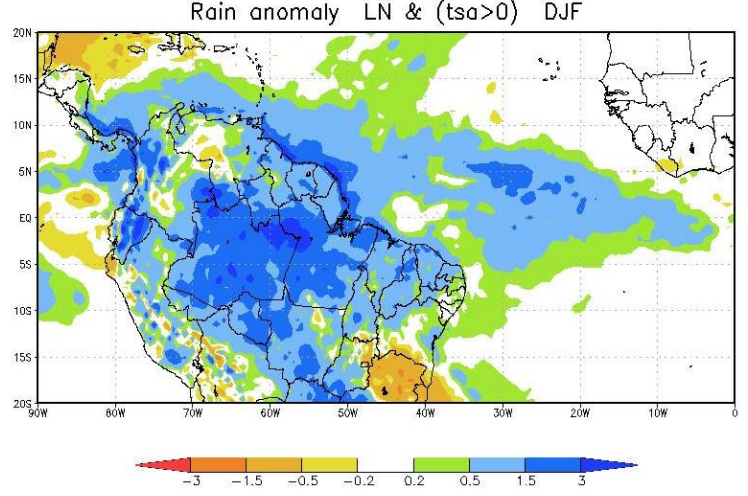

(c)

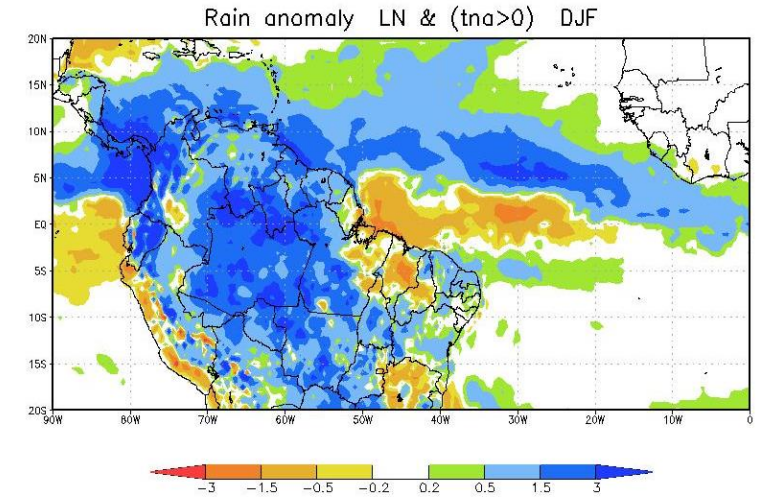

(e)

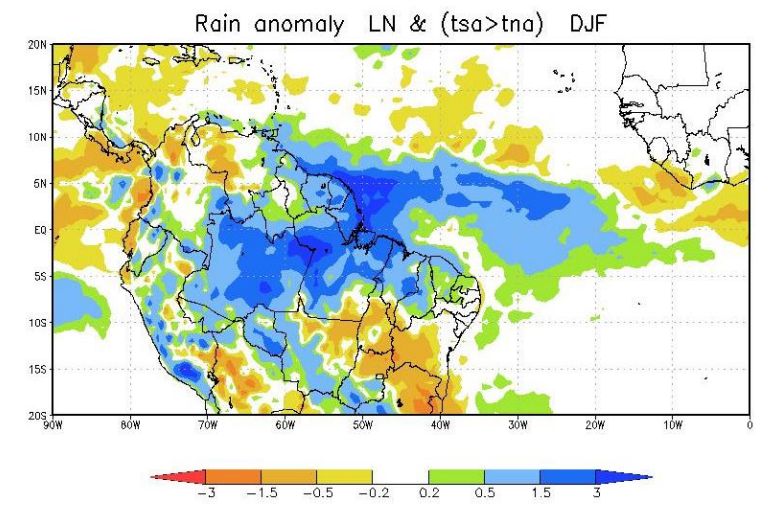

(b)

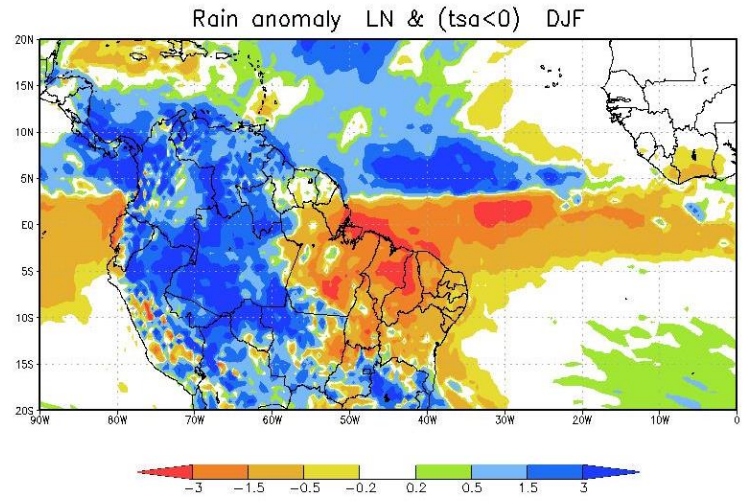

(d)

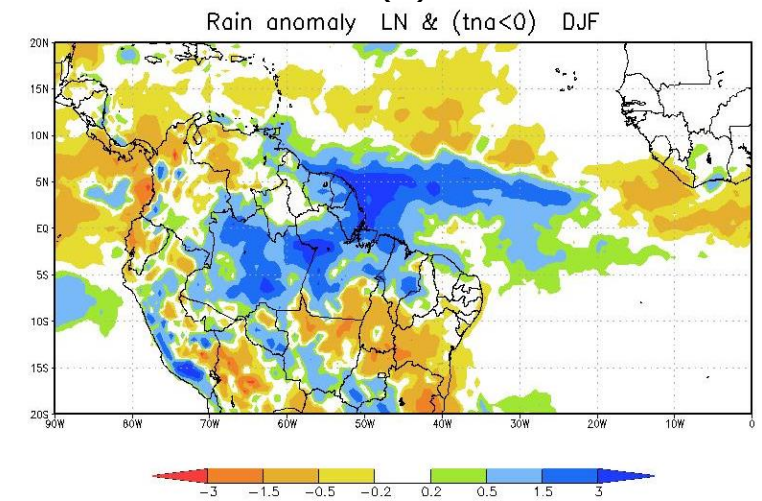

(f)

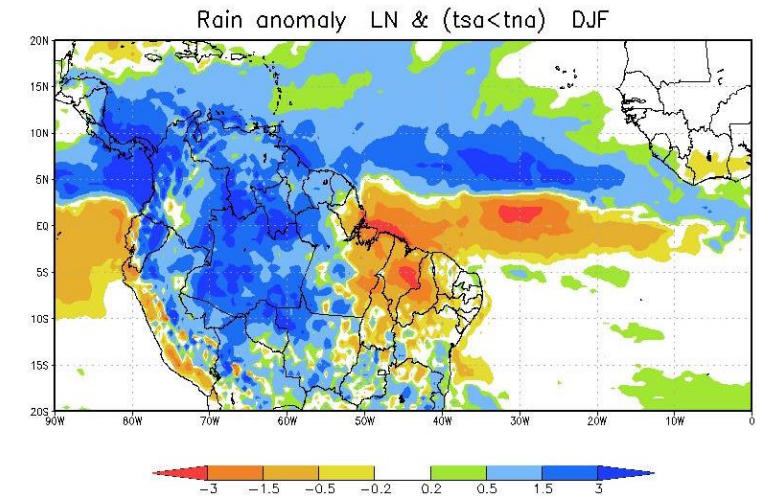

Figura 6 Anomalias da precipitação tropical $\left(\mathrm{mm} \mathrm{dia}^{-1}\right)$ em dezembro-janeiro-fevereiro de 1979 a 2011, com a La Niña coincidindo com: (a) TSA positiva, (b) TSA negativa, (c) TNA positiva e (d) TNA negativa, (e) diferença TSA-TNA positiva, e (f) diferença TSA-TNA negativa. 


\section{Controle das Teleconexões no Outono}

O trimestre março-abril-maio, representativo do outono tropical, é a época em que as chuvas são esperadas na região Nordeste do Brasil, sendo também quando a ZCIT se desloca para a sua posição mais austral, alcançando latitudes em torno de $5^{\circ} \mathrm{S}$.

Na ocorrência de EN e TSM do Atlântico Tropical sul anomalamente quente (Fig. 7a), há um aumento da precipitação no setor noroeste da região Amazônica e no Nordeste do Brasil (exceto no litoral), aparece uma tênue zona de convergência oceânica a partir do litoral da Bahia e a ZCIT fica restrita ao setor central do Atlântico. Enquanto isto, déficits de precipitação são registrados em quase toda a região Norte e litoral do Nordeste do Brasil. Anomalias de precipitação similares à descrita ocorrem com o TNA anomalamente quente, exceto pela ZCIT aparecer deslocada para norte (Fig. 7c). Quando coincide o EN com anomalias frias no TSA (Fig. 7b) ou no TNA (Fig. 7d), praticamente toda a Amazônia e o nordeste do Brasil ficam secos (sendo as anomalias negativas de precipitação mais intensas com TSA $<0$ ) e a ZCIT aparece deslocada para norte, quando esta deveria alcançar a sua posição mais ao sul nesta época do ano. É importante destacar que, comparando as anomalias de precipitação no nordeste do Brasil nos casos de TSA $<0$ e TSA $>0$, as condições secas se intensificam com 0 TSA $<0$. Considerando a situação TSA>TNA, a ZCIT aparece mais intensa ao norte das regiões Norte e Nordeste do Brasil, contribuindo para um excesso de precipitação no litoral do Pará e Maranhão; no restante do Brasil tropical tendem a dominar anomalias negativas de precipitação (Fig. 7e). O padrão da ZCIT se inverte com TSA<TNA, isto é, ela aparece enfraquecida no TSA e fortalecida no TNA, o que contribui para as intensas anomalias negativas de precipitação principalmente no setor norte das regiões Norte e Nordeste do Brasil (Fig. 7f).

A Figura 8 representa as anomalias da precipitação tropical em anos de LN sob condições de anomalias de TSM positivas ou negativas no Atlântico Tropical. Embora a condição de LN favoreça a chuva nos trópicos da América do Sul, se as anomalias de TSM no TSA ou no TNA estão negativas, há déficit de precipitação no noroeste do continente (Figs. 8 b-d). Vale destacar que na situação TSA $<0$, as anomalias negativas de precipitação também atuam sobre a maior parte da Região Norte do Brasil (Fig. 8b). No caso da ZCIT, que nesta época do ano deveria alcançar sua posição mais ao sul, esta fica enfraquecida quando TSA $<0$ (Fig. 8b), mas isso não impede que as chuvas sejam significativas sobre todo o nordeste brasileiro, exceto no Maranhão. Ainda nestas condições, a convecção no Caribe é acentuada. Já na situação TNA<0 (Fig. 8d), a ZCIT aparece vigorosa a partir das chuvas significativas no Nordeste do Brasil e também no Pará, no leste da Amazônia e no Tocantins. Quando TSA>0 ou TNA>0, há um enfraquecimento das anomalias negativas de precipitação no noroeste do continente e predominam condições úmidas sobre as regiões Norte e Nordeste do Brasil. Nessas situações a ZCIT parece deslocada para sul. Este padrão de anomalias de precipitação se repete com TSA $>$ TNA (Fig. 8e), mas se altera quando TSA $<$ TNA, ocorrendo anomalias secas em grande parte da Região Norte, sendo a ZCIT enfraquecida (Fig. 8f). 
ISSN: 1980-055x (Impressa) 2237-8642 (Eletrônica)

(a)

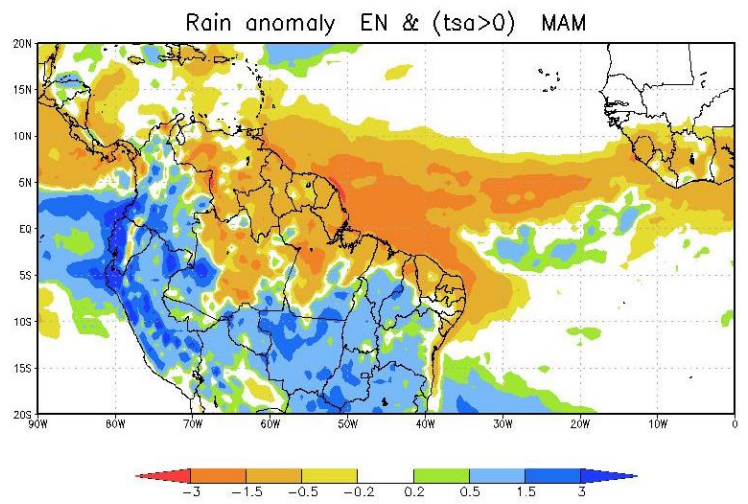

(c)

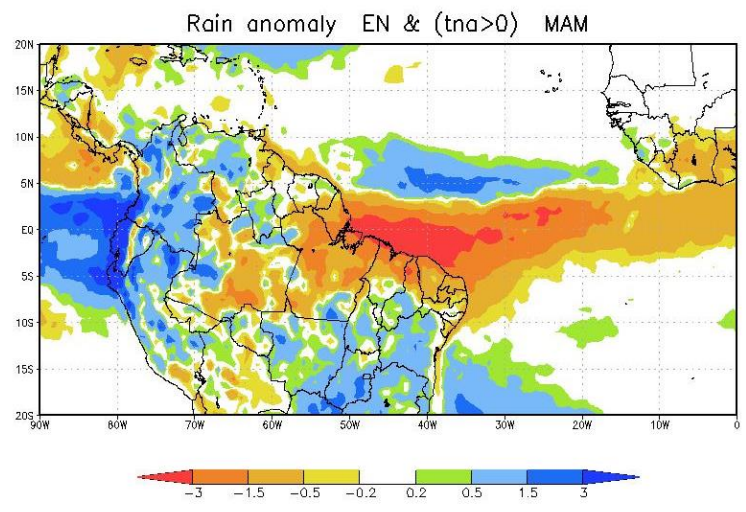

(e)

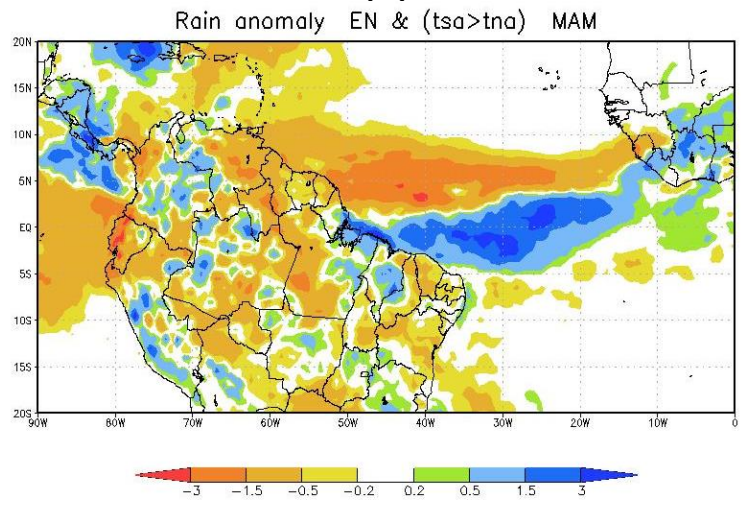

(b)

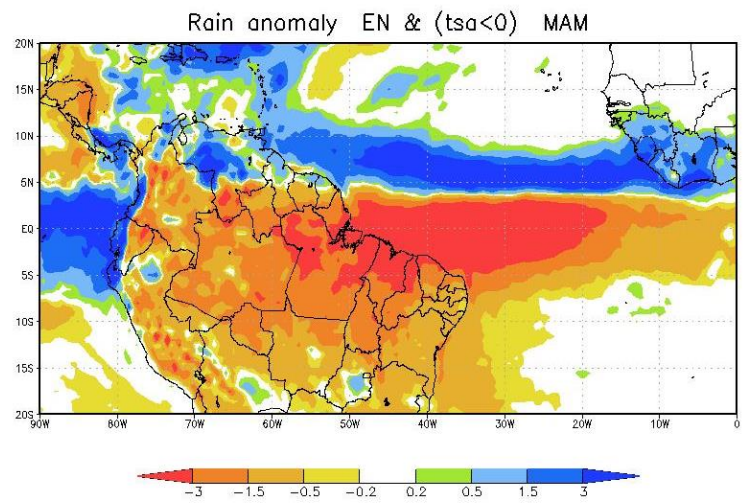

(d)

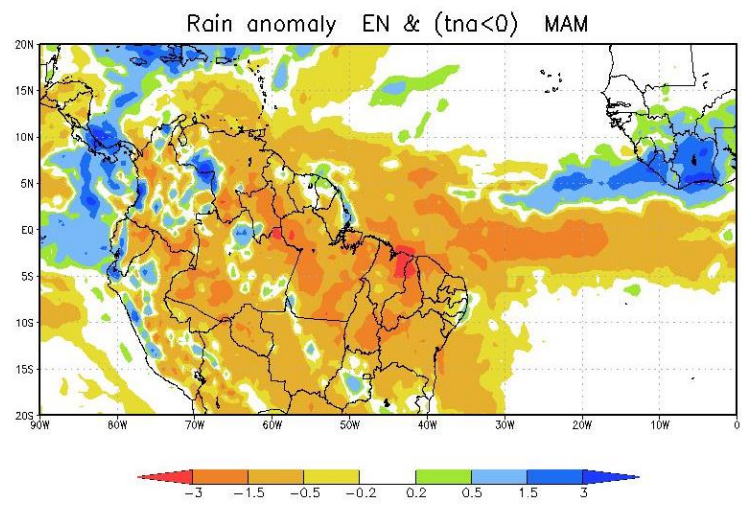

(f)

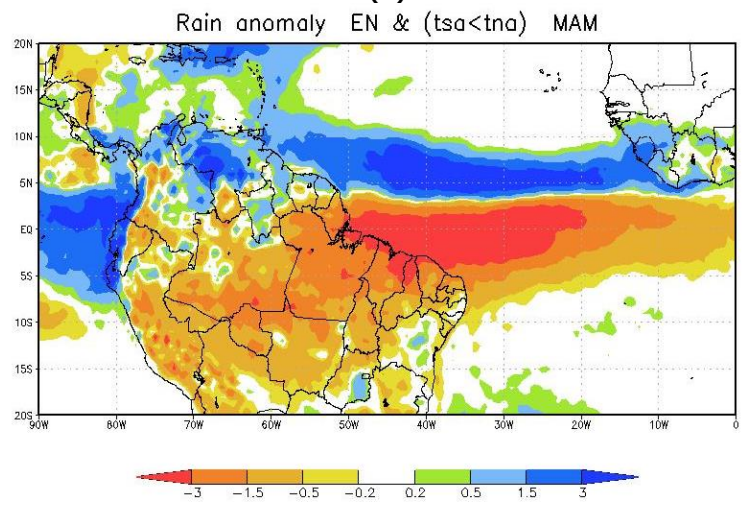

Figura 7 Anomalias da precipitação tropical $\left(\mathrm{mm} \mathrm{dia}^{-1}\right)$ em março-abril-maio de 1979 a 2011, com o El Niño coincidindo com: (a) TSA positiva, (b) TSA negativa, (c) TNA positiva e (d) TNA negativa, (e) diferença TSATNA positiva, e (f) diferença TSA-TNA negativa. 
(a)

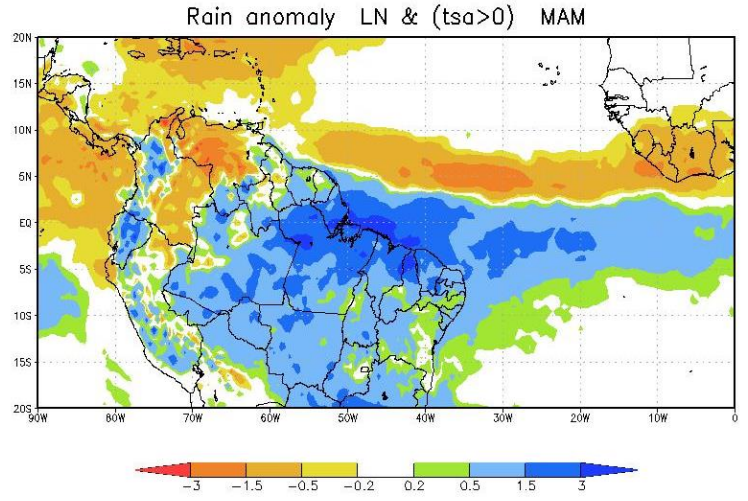

(c)

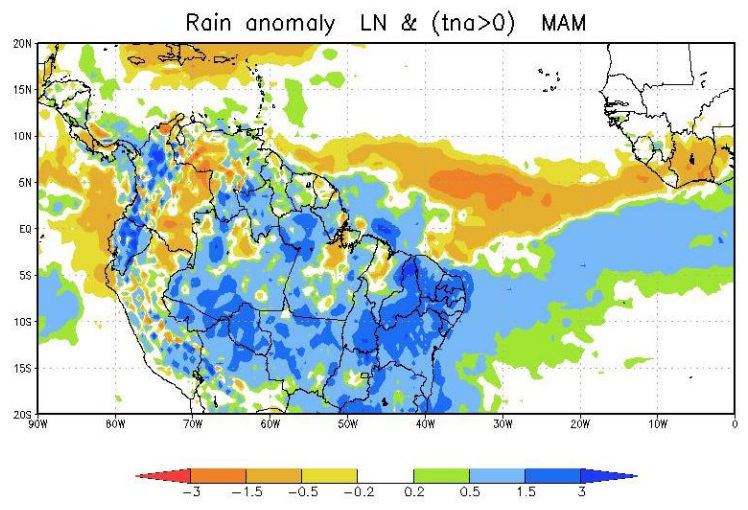

(e)

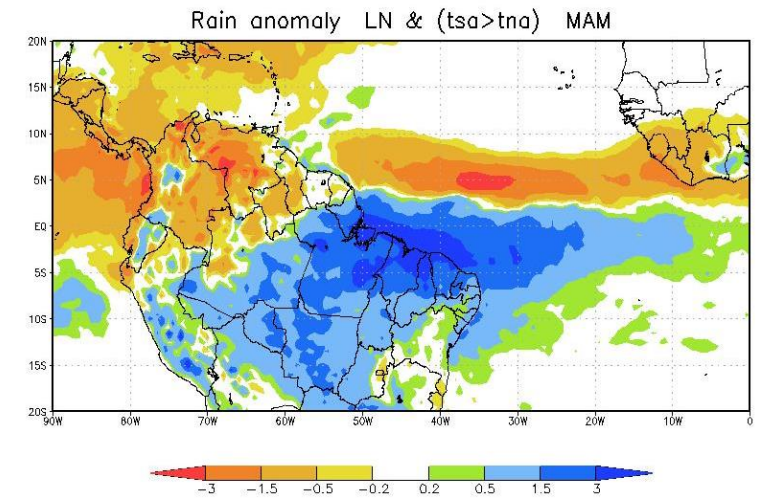

(b)

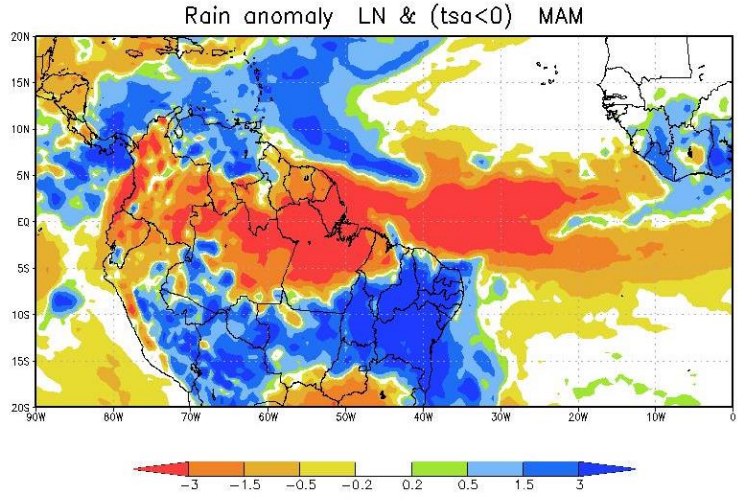

(d)

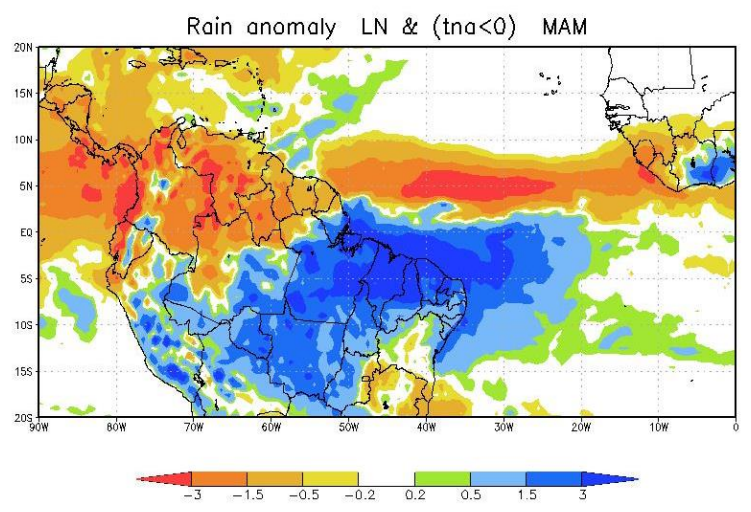

(f)

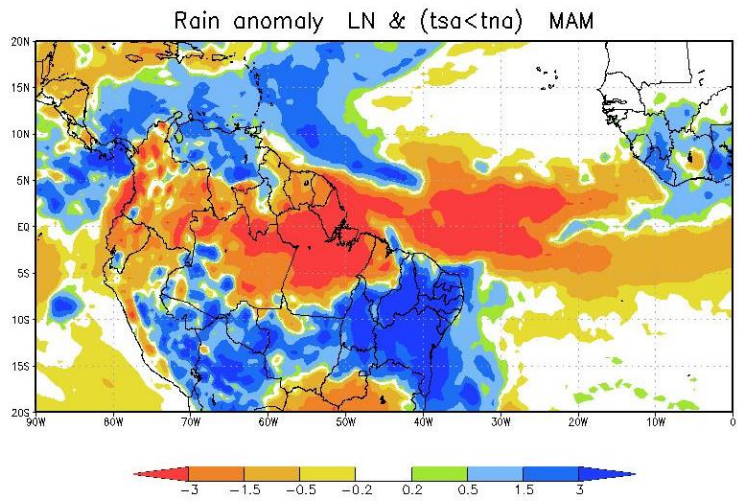

Figura 8 Anomalias da precipitação tropical $\left(\mathrm{mm} \mathrm{dia}^{-1}\right)$ em março-abril-maio de 1979 a 2011, com a La Niña coincidindo com: (a) TSA positiva, (b) TSA negativa, (c) TNA positiva e (d) TNA negativa, (e) diferença TSATNA positiva, e (f) diferença TSA-TNA negativa. 


\section{Conclusões}

Vários estudos têm indicado que a ocorrência de EN pode causar déficit de precipitação nas regiões Norte e Nordeste do Brasil, enquanto que a ocorrência de LN levaria ao excesso de precipitação. Entretanto, nem sempre isso é observado, pois a influência das anomalias de TSM do Atlântico Tropical sul e/ou norte se acopla ao efeito das anomalias de TSM do Pacífico Tropical, alterando ou fortalecendo o sinal das anomalias de precipitação sobre o Brasil tropical. Assim, o presente estudo documentou o efeito combinado das anomalias de TSM dos oceanos Pacífico e Atlântico Tropical, indicando as regiões que apresentam excesso ou déficit de precipitação. Os resultados obtidos foram sintetizados nos Quadros 1 e 2. 
Quadro 1 Resumo das condições anômalas de precipitação nas regiões Norte e Nordeste do Brasil em situações de anomalias positivas de TSM no oceano Pacífico Tropical central-leste e diferentes condições no Atlântico Tropical (especificadas na Tabela).

\begin{tabular}{|c|c|c|c|c|c|c|}
\hline \multirow{2}{*}{ Situações } & \multicolumn{2}{|c|}{ SON } & \multicolumn{2}{|c|}{ DJF } & \multicolumn{2}{|c|}{ MAM } \\
\hline & Região Norte & Região Nordeste & Região Norte & Região Nordeste & Região Norte & Região Nordeste \\
\hline EN e TSA $>0$ & $\begin{array}{c}\text { Déficit de chuva, } \\
\text { mas com excesso } \\
\text { no sudoeste da } \\
\text { Amazônia }\end{array}$ & $\begin{array}{c}\text { Déficit de chuva } \\
\text { no Maranhão, } \\
\text { Piauí e litoral } \\
\text { leste }\end{array}$ & Déficit de chuva & Déficit de chuva & $\begin{array}{c}\text { Déficit de chuva, } \\
\text { mas com excesso } \\
\text { no extremo oeste } \\
\text { da Amazônia }\end{array}$ & $\begin{array}{l}\text { Déficit de chuva } \\
\text { no litoral e } \\
\text { excesso no } \\
\text { interior dessa } \\
\text { região }\end{array}$ \\
\hline EN e TNA $>0$ & $\begin{array}{c}\text { Déficit de chuva, } \\
\text { mas com excesso } \\
\text { no estado do } \\
\text { Amazonas }\end{array}$ & $\begin{array}{l}\text { Déficit de chuva } \\
\text { no Maranhão, } \\
\text { Piauí e litoral } \\
\text { leste }\end{array}$ & Déficit de chuva & Déficit de chuva & $\begin{array}{c}\text { Déficit de chuva, } \\
\text { mas com excesso } \\
\text { no extremo oeste } \\
\text { da Amazônia }\end{array}$ & $\begin{array}{l}\text { Déficit de chuva } \\
\text { no litoral e } \\
\text { excesso no } \\
\text { interior dessa } \\
\text { região } \\
\end{array}$ \\
\hline EN e TSA $<0$ & Déficit de chuva & $\begin{array}{l}\text { Déficit de chuva } \\
\text { no Maranhão e } \\
\text { litoral da Bahia }\end{array}$ & $\begin{array}{l}\text { Déficit de chuva, } \\
\text { mas com excesso } \\
\text { no Tocantins }\end{array}$ & $\begin{array}{c}\text { Excesso de } \\
\text { chuva, mas com } \\
\text { déficit no } \\
\text { Maranhão }\end{array}$ & Déficit de chuva & Déficit de chuva \\
\hline EN e TNA $<0$ & $\begin{array}{c}\text { Déficit de chuva, } \\
\text { mas com excesso } \\
\text { no sudeste do } \\
\text { Pará e Tocantins }\end{array}$ & $\begin{array}{c}\text { Excesso de chuva } \\
\text { no Maranhão e } \\
\text { litoral leste, } \\
\text { exceto no litoral } \\
\text { da Bahia onde há } \\
\text { déficit }\end{array}$ & Déficit de chuva & Déficit de chuva & Déficit de chuva & Déficit de chuva \\
\hline EN e TSA $>$ TNA & $\begin{array}{c}\text { Déficit de chuva, } \\
\text { mas com excesso } \\
\text { no sudoeste de } \\
\text { Tocantins }\end{array}$ & $\begin{array}{c}\text { Excesso de chuva } \\
\text { no Maranhão e } \\
\text { litoral leste, } \\
\text { exceto no litoral } \\
\text { da Bahia onde há } \\
\text { déficit }\end{array}$ & Déficit de chuva & Déficit de chuva & $\begin{array}{l}\text { Déficit de chuva, } \\
\text { mas com ligeiro } \\
\text { excesso no } \\
\text { extremo oeste da } \\
\text { Amazônia }\end{array}$ & $\begin{array}{l}\text { Déficit de chuva, } \\
\text { mas excesso no } \\
\text { Maranhão }\end{array}$ \\
\hline EN e TSA < TNA & $\begin{array}{c}\text { Excesso de chuva } \\
\text { no setor oeste } \\
\text { dessa região e } \\
\text { déficit no setor } \\
\text { leste. }\end{array}$ & $\begin{array}{c}\text { Déficit de chuva } \\
\text { no Maranhão, } \\
\text { Piauí e oeste da } \\
\text { Bahia e excesso } \\
\text { no sul da Bahia }\end{array}$ & $\begin{array}{c}\text { Déficit de chuva, } \\
\text { mas com excesso } \\
\text { no Tocantins }\end{array}$ & Excesso de chuva & Déficit de chuva & Déficit de chuva \\
\hline
\end{tabular}


Quadro 2 Resumo das condições anômalas de precipitação nas regiões Norte e Nordeste do Brasil em situações de anomalias negativas de TSM no oceano Pacífico Tropical central-leste e diferentes condições no Atlântico Tropical (especificadas na Tabela).

\begin{tabular}{|c|c|c|c|c|c|c|}
\hline \multirow{2}{*}{ Situações } & \multicolumn{2}{|c|}{ SON } & \multicolumn{2}{|c|}{ DJF } & \multicolumn{2}{|c|}{ MAM } \\
\hline & Região Norte & Região Nordeste & Região Norte & Região Nordeste & Região Norte & Região Nordeste \\
\hline LN e TSA $>0$ & Excesso de chuva & $\begin{array}{c}\text { Excesso de chuva } \\
\text { no Maranhão, } \\
\text { Piauí e Bahia }\end{array}$ & Excesso de chuva & Excesso de chuva & Excesso de chuva & Excesso de chuva \\
\hline LN e TNA $>0$ & Excesso de chuva & $\begin{array}{c}\text { Excesso de chuva } \\
\text { no Maranhão, } \\
\text { Piauí e Bahia }\end{array}$ & Excesso de chuva & $\begin{array}{c}\text { Excesso de } \\
\text { chuva, mas com } \\
\text { déficit no } \\
\text { Maranhão e Piauí }\end{array}$ & Excesso de chuva & Excesso de chuva \\
\hline LN e TSA $<0$ & $\begin{array}{c}\text { Déficit de chuva, } \\
\text { mas com excesso } \\
\text { no sul do Pará e } \\
\text { Tocantins } \\
\end{array}$ & $\begin{array}{c}\text { Déficit no litoral } \\
\text { leste e excesso na } \\
\text { Bahia }\end{array}$ & $\begin{array}{c}\text { Excesso de } \\
\text { chuva, mas com } \\
\text { déficit no Pará e } \\
\text { Tocantins }\end{array}$ & Déficit de chuva & $\begin{array}{c}\text { Déficit de chuva, } \\
\text { mas com excesso } \\
\text { no extremo oeste } \\
\text { da Amazônia }\end{array}$ & $\begin{array}{c}\text { Excesso de } \\
\text { chuva, mas com } \\
\text { déficit no } \\
\text { Maranhão } \\
\end{array}$ \\
\hline LN e $T N A<0$ & Excesso de chuva & $\begin{array}{c}\text { Excesso de chuva } \\
\text { no Maranhão, } \\
\text { Piauí e oeste da } \\
\text { Bahia }\end{array}$ & $\begin{array}{c}\text { Excesso de } \\
\text { chuva, mas com } \\
\text { déficit no sudeste } \\
\text { do Pará e } \\
\text { Tocantins }\end{array}$ & $\begin{array}{c}\text { Excesso de chuva } \\
\text { no Maranhão, } \\
\text { Piauí e litoral do } \\
\text { Ceará e déficit na } \\
\text { Bahia }\end{array}$ & $\begin{array}{c}\text { Excesso de } \\
\text { chuva, mas com } \\
\text { déficit no } \\
\text { noroeste da } \\
\text { Amazônia }\end{array}$ & $\begin{array}{c}\text { Excesso de } \\
\text { chuva, mas com } \\
\text { condições } \\
\text { normais em } \\
\text { quase toda a } \\
\text { Bahia } \\
\end{array}$ \\
\hline LN e TSA $>$ TNA & $\begin{array}{c}\text { Excesso de } \\
\text { chuva, mas com } \\
\text { ligeiro déficit no } \\
\text { sudoeste do } \\
\text { Amazonas }\end{array}$ & $\begin{array}{c}\text { Excesso de chuva } \\
\text { no Maranhão, } \\
\text { Piauí e oeste e } \\
\text { litoral da Bahia }\end{array}$ & $\begin{array}{c}\text { Excesso de } \\
\text { chuva, mas com } \\
\text { déficit no sudeste } \\
\text { do Pará e } \\
\text { Tocantins }\end{array}$ & $\begin{array}{c}\text { Excesso de chuva } \\
\text { no Maranhão, } \\
\text { Piauí e Ceará e } \\
\text { déficit na Bahia }\end{array}$ & $\begin{array}{c}\text { Excesso de } \\
\text { chuva, mas com } \\
\text { déficit no } \\
\text { noroeste da } \\
\text { Amazônia }\end{array}$ & $\begin{array}{c}\text { Excesso de } \\
\text { chuva, mas com } \\
\text { condições } \\
\text { normais em } \\
\text { quase toda a } \\
\text { Bahia } \\
\end{array}$ \\
\hline LN e TSA $<$ TNA & Excesso de chuva & $\begin{array}{c}\text { Excesso de chuva } \\
\text { no Maranhão, } \\
\text { Piauí e Bahia }\end{array}$ & $\begin{array}{c}\text { Excesso de } \\
\text { chuva, mas com } \\
\text { déficit no leste do } \\
\text { Pará e Tocantins }\end{array}$ & $\begin{array}{c}\text { Déficit de chuva, } \\
\text { mas com excesso } \\
\text { no litoral do Rio } \\
\text { Grande do Norte } \\
\text { e sul da Bahia }\end{array}$ & $\begin{array}{l}\text { Déficit de chuva, } \\
\text { mas com excesso } \\
\text { no oeste do } \\
\text { Amazonas }\end{array}$ & $\begin{array}{c}\text { Excesso de } \\
\text { chuva, mas com } \\
\text { déficit no } \\
\text { Maranhão }\end{array}$ \\
\hline
\end{tabular}




\section{REFERÊNCIAS}

ANDREOLI, R. V.; KAYANO, M. T. A importância relativa do Atlântico Tropical Sul e Pacífico Leste na variabilidade do Nordeste do Brasil. Revista Brasileira de Meteorologia, v. 22, n. 01, p. 63-74, 2007.

ÅNGSTRÖM, A. Teleconnections of climate changes in present time. Geography Annals, v. 17, p 242- 258, 1935.

CAVALCANTI, I. F. A. Large scale and synoptic features associated with extreme precipitation over South America: A review and case studies for the first decade of the 21st century. Atmospheric Research, v. 118, p. 27-40, 2012.

BJERKNES, J. Atmospheric teleconnections from the equatorial Pacific. Monthly Weather Review, v. 97, n. 3, p. 163-172, 1969.

ENFIELD, D. B. et al. How ubiquitous is the dipole relationship in tropical Atlantic sea surface temperatures? Journal of geophysical research, v. 104, p. 7841-7848, 1999.

FOLEY, J. A. et al. El Niño-Southern oscillation and the climate, ecosystems and rivers of Amazonia. Global Biogeochemical Cycles, v. 16, p. 79-1 - 79-20, 2002.

GRIMM, A. M.; AMBRIZZI, T. Teleconnections into South America from the Tropics and Extratropics on Interannual and Intraseasonal Timescales. In: Vimeux F, Sylvestre $F$, Khodri M

(eds) Past Climate Variability in South America and Surrounding Regions: From the Last Glacual Maximum to the Holocene. v. 14, p 159-191. 2009.

GRIMM, A. M.; TADESCHI, R. G. ENSO and Extreme Rainfall Events in South America. Journal of Climate, v. 22, p. 1589-1609, 2009.

HOREL, J. D.; WALLACE, J. M. Planetary scale atmospheric phenomena associated with the Southern Oscillation. Monthly Weather Review, v. 109: p. 813-829, 1981.

HOSKINS, B. J.; KAROLY, D. J. The steady linear responses of a spherical atmosphere to thermal and orographic forcing. Journal of the Atmospheric Sciences, v. 38, p. 1179-1196, 1981.

KANE, R. P. El Niño and La Niña events and rainfall in NE and South Brazil. Revista Brasileira de Geofísica, v.10, p.49-59, 1992.

LIU, Z.; ALEXANDER, M. Atmospheric bridge, oceanic tunnel, and global climatic teleconnections. Reviews of Geophysics, v. 45, 2007.

MANTUA, N. J. et al. A Pacific interdecadal climate oscillation with impacts on salmon production. Bulletin of the American Meteorological Society, v. 78, n. 6, p. 1069-1079, 1997.

MARENGO, J. A. et al. The Drought of Amazonia in 2005. Jornal of Climate, v. 21, p. 495-516, 2008. 
MCPHADEN, M. J. El Niño and La Niña: Causes and global consequences. Encyclopedia of Global Environmental Change, Anonymous John Wiley and Sons, LTD, p. 353-370, 2002.

MO, K. C.; HIGGINS, R. W. The Pacific-South American Modes and Tropical Convection during the Southern Hemisphere Winter. Monthly Weather Review, v. 126, p. 15811596, 1998.

MOURA, A. D.; SHUKLA, J. On the dynamics of droughts in Northeast Brazil: Observations,

theory and numerical experiments with a general circulation model. Journal of the Atmospherical Sciences, Boston, v. 38, p.2653-2675, 1981.

PEZZI, L. P.; CAVALCANTI, I. F. A. The relative importance of ENSO and tropical Atlantic sea surface temperature anomalies for seasonal precipitation over South America: a numerical study. Climate Dynamics, v. 17, n. 2-3, p. 205-212, 2001.

PHILANDER, S. G. H. El Niño and La Niña. Journal of the Atmospheric Sciences, v. 42, p. 2652-2662, 1985.

PHILANDER, S. G. El Niño, La Niña, and the Southern Oscillation. San Diego: Academic Press, 1990.

RAO, V. B.; HADA, K. Characteristics of rainfall over Brazil: Annual variations and connections with the Southern Oscillation. Theoretical and Applied Climatology, v. 42, n. 2, p. 81-91, 1990.

REBOITA, M. S.; AMBRIZZI, T.; ROCHA, R. P. Relationship between the southern annular mode and southern hemisphere atmospheric systems. Revista Brasileira de Meteorologia, v. 24, n. 1, p. 48-55, 2009.

REBOITA, M. S. et al. Regimes de precipitação na América do Sul: uma revisão bibliográfica. Revista Brasileira de Meteorologia, v. 25, n. 2, p. 185-204, 2010.

SAJI, N. H. et al. A dipole mode in the tropical Indian Ocean. Nature, v. 401, p $360-$ $363,1999$.

SILVA, V. B. S., KOUSKY, V. E.; HIGGINS, R. W. Daily Precipitation Statistics for South America: An Intercomparison between NCEP Reanalyses and Observations. Journal of Hydrometeorology, v. 12, p. 101-117, 2011.

SOUZA, E. B.; AMBRIZZI, T. A precipitação observada no Norte-Nordeste do Brasil durante episódios simultâneos de ENOS no Pacífico e do Dipolo de anomalias de TSM no Atlântico. In: XII Congresso Brasileiro de Meteorologia, 2002, Foz do Iguaçú. A Meteorologia e a Gestão de Energia. Rio de Janeiro, RJ: SBMET, 2002.

THOMPSON, D.W.J.; WALLACE, J. M. Annular modes in the extratropical circulation. Part I: month-to-month variability. Journal of Climate, v. 13, n. 5, p. 1000-1016, 2000. 
TRENBERTH, K. E.; CARON, J. M. The Southern Oscillation Revisited: Sea Level Pressures, Surface Temperatures, and Precipitation. National Center for Atmospheric Research, *Boulder, Colorado. Journal of Climate. Vol 13, 2000.

TRENBERTH, K. E. The definition of el nino. Bulletin of the American Meteorological Society, v. 78, n. 12, p. 2771-2777, 1997.

UVO, C. B. et al. The relationships between tropical Pacific and Atlantic SST and northeast Brazil monthly precipitation. Journal of Climate, v. 11, n. 4, p. 551-562, 1998.

UVO, C. B.; TÖLLE, U.; BERNDTSSON, R. Forecasting discharge in Amazonia using artificial neural networks. International Journal of Climatology, v. 20, n. 12, p. 14951507, 2000.

VERA, C. et al. Toward a unified view of the American monsoon systems. Journal of Climate, v. 19, n. 20, p. 4977-5000, 2006.

YOON, J.; ZENG, N. An Atlantic influence on Amazon rainfall. Climate Dynamics, v. 34, n. 2-3, p. 249-264, 2010. 